

\title{
Characteristics and Engineering Performance of C-S-H/Aminobenzoic Acid Composite Systems
}

\author{
Rahil Khoshnazar $^{1 *}$, James J. Beaudoin ${ }^{1}$, Laila Raki ${ }^{1}$ and Rouhollah Alizadeh ${ }^{2}$
}

\begin{abstract}
Calcium-silicate-hydrate/aminobenzoic acid (C-S-H/ABA) composite systems were synthetized and characterized for the first time. Each of 3- or 4-aminobenzoic acid with a concentration of 0.01 mol. per mol. of Ca was added to the C-S-H preparations during their hydration. The C-S-H/ABA systems were filtered and dried after three weeks. These were, then, characterized by X-ray diffraction, Fourier transform infrared spectroscopy and nitrogen adsorption analysis. Porous bodies were also prepared from $\mathrm{C}-\mathrm{S}-\mathrm{H} / \mathrm{ABA}$ compacted powders and used for the length-change and mass-change measurements in different test solutions. In addition, the microindentation technique was used to determine the creep modulus and hardness of the compacted samples. It is suggested that the C-S-H/ABA systems had improved durability and enhanced mechanical properties compared to the phase pure C-S-H reference materials. The influence of the 3- and 4-aminobenzoic acid on durability factors was similar. The C-S-H/3-ABA, however, had superior mechanical performance.
\end{abstract}

\section{Introduction}

Calcium-silicate-hydrate $(\mathrm{C}-\mathrm{S}-\mathrm{H})$ is the primary binding phase in the hydrated Portland cement. The improvement of properties of C-S-H is of significant interest as it can directly influence the performance of cement-based construction materials. Modification of the nanostructure of $\mathrm{C}-\mathrm{S}-\mathrm{H}$ by organic compounds is likely to be a promising approach to achieve this goal (Matsuyama and Young 1999a-c; Mojumdar and Raki 2006; Alizadeh et al. 2011). Several organic compounds have been previously used successfully to modify/improve the nanostructure of smectic clays (Okada et al 1990; Somwangthanaroj 2010; Natkanski 2012; LeBaron 1999). The use of these organics for the modification of the C-S-H structure has potential based on the similarities between the layered structure of C-S-H and that of the smectic clays (Taylor 1997; Feldman and Sereda 1970).

Several studies have been conducted during the past two decades with a focus on the physico-chemistry of the $\mathrm{C}-\mathrm{S}-\mathrm{H} /$ organic systems. In spite of this work, the nature of the various types of interaction of organic compounds with the structure of C-S-H is still unclear. It was suggested by Matsuyama and Young (1999a-c) that certain polymers are able to intercalate the interlayer region of $\mathrm{C}-\mathrm{S}-\mathrm{H}$ systems prepared by the precipitation technique. More recent investigations, however, provided evidence that the intercalation of organic compounds in the layered structure of C-S-H is much more difficult than that in smectic clays. It was suggested by Merlin et al. (2002) that this could be due to the higher charge of the layers in

\footnotetext{
${ }^{1}$ National Research Council Canada, Ottawa, ON, Canada, K1A 0R6.

*Corresponding author, E-mail: rkhos017@uottawa.ca

${ }^{2}$ Giatec Scientific Inc., Ottawa, Canada, K2H 9R4.
}

the C-S-H structure and the localization of the charge on the surface of the layers in the structure of C-S-H as opposed to the distribution of the charge within the layers as is the case for smectic clays. These two reasons could make the intercalation very difficult to achieve. It was, however, observed that a significant amount of the organics could be adsorbed in the stacked layers of C-S-H. In addition, it was suggested by Minet et al. (2004, 2006) that trialkoxysilane compounds were able to form covalent bonds with silicate tetrahedra in the structure of $\mathrm{C}-\mathrm{S}-\mathrm{H}$. The formation of these bonds was more probable when these organic compounds had a smaller size. A comprehensive investigation of the characteristics of covalent-bonded polymer-C-S-H composites was also provided by Franceschini et al. (2007). A study of the engineering performance of these composite systems, however, is still lacking.

It was recently suggested by the authors that different isomers of nitrobenzoic acid could be successfully used to interact with the nanostructure of C-S-H (Khoshnazar et al. 2014a). Significant improvement of the durability and mechanical performance of the C-S-H-based systems was observed due to the incorporation of nitrobenzoic acid with the concentration of $0.01 \mathrm{~mol}$. per mol. of Ca of the C-S-H (Khoshnazar 2015). Aminobenzoic acid (ABA) has a similar molecular size and structure to the nitrobenzoic acid (NBA). However, the amino group is electropositive and an activating group of the aromatic ring. This is opposite to the electronegative properties of the nitro group resulting in deactivation of the aromatic ring in the nitrobenzoic acid molecule (Samsonowicz et al. 2005, 2007). It has been suggested that the acidity of the aminobenzoic acid isomers, increases in the order of 3-ABA > 4-ABA > 2-ABA (Samsonowicz et al. 2005). The acidity of the nitrobenzoic acid isomers, however, increases in the opposite order (2-NBA > 4-NBA > 3-NBA) (Samsonowicz et al. 2007). 
It was suggested by Ramachandran et al. (1999) that the 3- and 4-aminobenzoic acid isomers are retarders of the hydration process of $\mathrm{C}_{3} \mathrm{~S}$. The influence of these aminobenzoic acid isomers on the microstructure and engineering properties of synthetic C-S-H systems was investigated in the current study for the first time. The C-S-H/3-ABA and C-S-H/4-ABA systems were synthesized using a pozzolanic reaction technique. Their characteristics and engineering performance were compared with those obtained for the phase pure C-S-H.

\section{Experimental program}

\subsection{Materials}

Phase pure C-S-H, C-S-H/3-ABA and C-S-H/4-ABA systems $(\mathrm{Ca} / \mathrm{Si}=1.5)$ were synthesized using the pozzolanic reaction technique. It included the reaction of stoichiometric amounts of calcium oxide and colloidal silica in excess water (water/solid mass $\approx 10$ ) for 21 days. Calcium oxide was obtained by calcining calcium carbonate (reagent grade, Fisher Scientific) at $900^{\circ} \mathrm{C}$ for 24 hours. Reactive colloidal silica (CAB-O-SIL ${ }^{\circledR}$, grade M-5) was provided by Cabot Corporation. Powders of calcium oxide and colloidal silica were first dry-mixed in a high density polyethylene (HDPE) bottle. De-ionized out-gassed water was, then, added to the solid mixture to initiate the pozzolanic reaction. Either of 3- or 4-aminobenzoic acid (reagent grade, Sigma-Aldrich) with the concentration of $0.01 \mathrm{~mol}$. per mol. of $\mathrm{Ca}$ (in the $\mathrm{C}-\mathrm{S}-\mathrm{H}$ ) was pre-mixed with the water to prepare the $\mathrm{C}-\mathrm{S}-\mathrm{H} / \mathrm{ABA}$ systems. It was previously suggested by the authors that the NBA isomers with a concentration of 0.01 mol. per mol. of $\mathrm{Ca}$ (in the C-S-H) had higher interaction effects with the structure of C-S-H (Khoshnazar et al. 2014a). This concentration was also selected for the study of the ABA isomers because of the similarities between the molecular size and structure of the NBA and ABA organic compounds.

The solutions were agitated for 21 days at room temperature. They were, then, filtered and dried under vacuum for four hours. The gel-like products were conditioned in sealed desiccators at the relative humidity of $11 \%$ (over saturated lithium chloride solution) for 40 days. The C-S-H/3-ABA and C-S-H/4-ABA systems had a pinkish and yellowish color, respectively, which was different from the white color of the phase pure C-S-H.

\subsection{Experiments}

All the C-S-H-based systems were characterized using X-ray diffraction (XRD), Fourier transform infrared spectroscopy (FTIR) and nitrogen adsorption analysis. Circular compacted samples of the powder were prepared using a compaction technique described by Sereda and Feldman (1963). The diameter and thickness of the compacted samples were $32 \mathrm{~mm}$ and $1 \mathrm{~mm}$, respectively. The compaction load was adjusted to reach a porosity of about 30\% determined using the helium pycnometer technique (Sereda and Feldman 1963). Length-change of the compacted samples in $\mathrm{MgSO}_{4}$ and $\mathrm{LiCl}$ solutions (15 $\mathrm{g} / \mathrm{l})$ was measured up to 7 days. The mass-change of the samples in isopropyl alcohol was also determined as an estimation of the resistance of the samples to the diffusion of aggressive ions. The microindentation technique was also used to measure the creep modulus and hardness of the compacted samples. Details of the experiments are as following:

(1) XRD - The X-ray diffraction pattern of the C-S-H-based systems was acquired using a Scintag XDS 2000 diffractometer $\left(\mathrm{CuK}_{\alpha}\right.$ radiation). The test was performed in a $2 \theta$ ranging $4^{\circ}<2 \theta<15^{\circ}$, with a step size of $0.03^{\circ}$ and a 5 second count interval to detect the changes in the basal-spacing $\left(\mathrm{d}_{002}\right)$ peak.

(2) FTIR - Fine powders were mixed with potassium bromide, and compacted into a disk of $10 \mathrm{~mm}$ diameter using a 10 ton load. FTIR spectra were collected between 4000 and $400 \mathrm{~cm}^{-1}$ using a Tensor 27 spectrometer in direct transmission mode. Each FTIR spectrum represented the average of 50 scans at $4 \mathrm{~cm}^{-1}$ resolution. Air was used as a background for the measurements.

(3) Nitrogen adsorption - The nitrogen adsorption measurements were obtained using a Quantachrome instrument NOVA 2200e surface area and pore size analyzer. The samples were vacuum dried at $110^{\circ} \mathrm{C}$ for three hours prior to starting the tests. Then, the nitrogen BET (Brunauer-Emmett-Teller) surface area analysis was performed on each sample.

(4) Diffusion of isopropyl alcohol - The diffusion of isopropyl alcohol into the compacted samples was evaluated by the measurement of the mass-change of the samples following immersion in the isopropyl alcohol. Each compacted circular sample preconditioned to $11 \%$ relative humidity was placed in a small stainless steel basket, and immersed in $450 \mathrm{ml}$ of anhydrous isopropyl alcohol (Reagent grade, Fischer Scientific). About 100 $\mathrm{ml}$ of the isopropyl alcohol covered the samples (The sample was at the depth of $20 \mathrm{~mm}$ from the free surface of the isopropyl alcohol solution.) The set-up was attached to a balance and a data recorder to measure the mass-change of the samples for two hours after the immersion. Diffusion of isopropyl alcohol in saturated cement paste samples was previously used successfully to evaluate the resistance of the samples to the diffusion of chloride ion (Feldman 1987).

(5) Length-change measurements - Prisms ( $5 \mathrm{~mm} \times 25$ $\mathrm{mm} \times 1 \mathrm{~mm})$ were cut from the compacted discs and mounted on modified Tuckerman extensometers. Strains were determined with an accuracy of 1 microstrain (Khoshnazar et al. 2014b, Feldman et al 1964). These were, then, placed in small vessels containing the test solutions so that the specimens were completely immersed. Aqueous solutions of $\mathrm{MgSO} 4$ and $\mathrm{LiCl}$ with a concentration of $15 \mathrm{~g} / 1$ were used as the test solution. The ratio of the mass of solid to the volume of solution was 1 $\mathrm{g}$ of solid per $50 \mathrm{ml}$ of the solution. The vessels were placed in sealed desiccators containing the same salt solution as the test solution to avoid evaporation. The 
length-change of the samples in each solution was measured up to 7 days.

(6) Microindentation measurements - The microindentation tests were performed using a CSM Instruments Indentation Tester. A Berkovich indenter was used for the measurements. The whole apparatus is housed in an environmental chamber. Circular compacted samples equilibrated at a relative humidity of $11 \%$ were used for the microindentation measurements.

A total of 25 indents were obtained on each sample. The indentation depth $(h)$ was recorded as a function of time $(t)$ at the maximum load of $1 \mathrm{~N}$ for a $600 \mathrm{~s}$ dwell period. The loading rate was $2 \mathrm{~N} / \mathrm{min}$. The creep was determined by curve fitting of the indentation-depth versus time curves during the loading period using $\Delta h(t)=x_{1} \ln \left(x_{2} t+1\right)+x_{3} t+x_{4}$. The creep modulus, $C$, was then calculated from $C=P_{\max } /\left(2 a_{u} x_{1}\right)$ where $P_{\max }$ is the maximum load and $a_{u}=\left(a_{c} / \pi\right)^{1 / 2} \cdot a_{c}$ is the projected area of contact between the indenter probe and the indenter surface. It is determined using the Oliver and Pharr method as a function of the maximum indentation depth (Vandamme 2008, Oliver and Pharr 1992). In addition, the indentation hardness $(H)$ was obtained from the software by $H=P / a_{c}$.

\section{Results}

\subsection{XRD}

The XRD patterns of the phase pure C-S-H and C-S-H/ABA systems are presented in Fig. 1. The $\mathrm{d}_{002}$ basal-spacing increased from $1.10 \mathrm{~nm}$ in the phase pure $\mathrm{C}-\mathrm{S}-\mathrm{H}$ to $1.13 \mathrm{~nm}$ and $1.17 \mathrm{~nm}$ in the C-S-H/3-ABA and C-S-H/4-ABA systems, respectively. An additional small peak was also observed at about $1.18 \mathrm{~nm}$ in the XRD pattern of the C-S-H/3-ABA system. It was likely due to

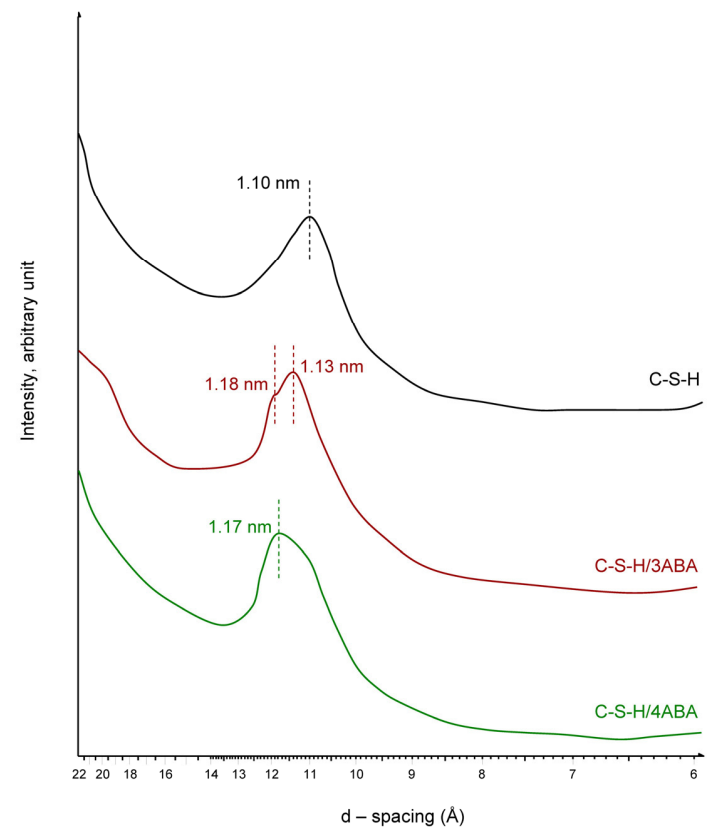

Fig. 1 XRD patterns of the phase pure C-S-H and the C-S-H/ABA systems. the occurrence of a second configuration of the 3-aminobenzoic acid molecule in the structure of $\mathrm{C}-\mathrm{S}-\mathrm{H} / 3-\mathrm{ABA}$ system. The small increment in the basal-spacing might have been due to the adsorption of the aminobenzoic acid at the edges of the C-S-H layers. Partial intercalation of the aminobenzoic acid was also possible because of the small size of this compound and also the relatively large number of defect locations in the structure of $\mathrm{C}-\mathrm{S}-\mathrm{H}$ with $\mathrm{Ca} / \mathrm{Si}$ ratio of 1.5 . The aminobenzoic acid could also be adsorbed between the stacked layers of C-S-H without any significant change in the basal-spacing. It is also noted that locations of the $\mathrm{d}_{002}$ basal-spacing of the C-S-H/3-ABA and C-S-H/4-ABA systems were similar to those observed for the C-S-H/3-NBA and C-S-H/4-NBA systems, respectively, as reported in a previous study (Khoshnazar et al. 2014a). This could be expected due to the similar size and structure of the aminobenzoic acid and the nitrobenzoic acid compounds.

\subsection{FTIR}

The FTIR spectra of the C-S-H/ABA systems were generally similar to that of the phase pure C-S-H (Fig. 2). The peaks at the wavelengths of $820 \mathrm{~cm}^{-1}$ and $988 \mathrm{~cm}^{-1}$ in the structure of C-S-H are assigned to the Si-O stretching of $\mathrm{Q}^{1}$ and $\mathrm{Q}^{2}$, respectively (Yu et al. 1999). The locations of these peaks were shifted slightly to the lower wavelengths $\left(816 \mathrm{~cm}^{-1}\right.$ and $\left.984 \mathrm{~cm}^{-1}\right)$ in the systems with 3 - or 4-aminobenzoic acid. In addition, the ratio of $\mathrm{Q}^{2} / \mathrm{Q}^{1}$ peaks are slightly larger in the $\mathrm{C}-\mathrm{S}-\mathrm{H} / \mathrm{ABA}$ systems compared to that in the phase pure C-S-H.

The peak at about $3645 \mathrm{~cm}^{-1}$ is sharper in the FTIR spectra of C-S-H/ABA systems compared to that in the spectra of the phase pure C-S-H. This peak is assigned to the relatively weak hydrogen-bonded interlayer water molecules (Yu et al. 1999). The higher intensity of this peak in the spectra of the C-S-H/ABA systems could be due to some weak hydrogen bonding of the aminobenzoic acid with the structure of the host C-S-H. The peak at $1595 \mathrm{~cm}^{1}$ in the FTIR spectra of C-S-H/4-ABA can be due to the symmetric in-plane deformations of $\mathrm{NH}_{2}$ in the structure of 4-aminobenzoic acid (Samsonowicz et al.

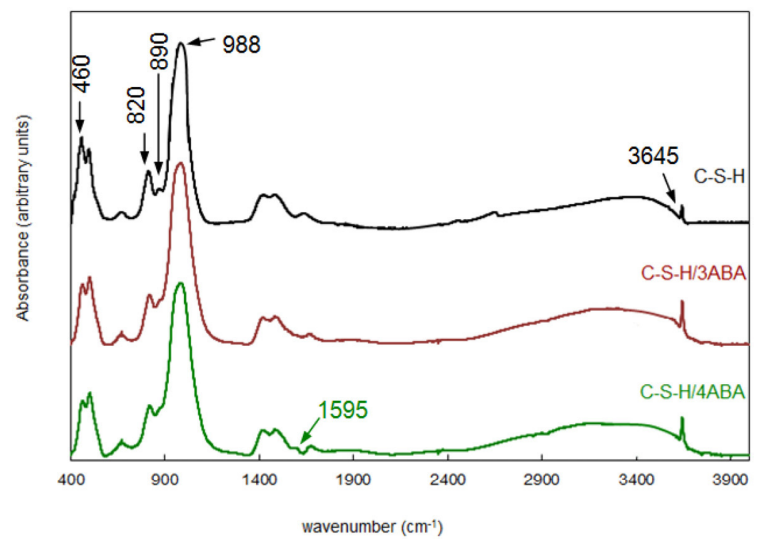

Fig. 2 FTIR spectra of the phase pure C-S-H and the C-S-H/ABA systems. 
2005). The peaks at the wavelengths of about $460 \mathrm{~cm}^{-1}$ and $890 \mathrm{~cm}^{-1}$ correspond to carbonates (Yu et al. 1999). Carbonation of the C-S-H-based systems likely occurred during the sample preparation. The higher intensity of these peaks in the FTIR spectra of the phase pure C-S-H was expected due to the higher surface area of the phase pure $\mathrm{C}-\mathrm{S}-\mathrm{H}$ compared to the $\mathrm{C}-\mathrm{S}-\mathrm{H} / \mathrm{ABA}$ systems (see section 3-3).

\subsection{Nitrogen adsorption analysis}

The BET nitrogen surface area of the phase pure C-S-H and the C-S-H/ABA systems are presented in Fig. 3. The surface area values of the C-S-H systems incorporating 3 - and 4-aminobenzoic acid were very similar $\left(35.6 \mathrm{~m}^{2} / \mathrm{g}\right.$ and $34.5 \mathrm{~m}^{2} / \mathrm{g}$ for the C-S-H/3-NBA and C-S-H/4-NBA system, respectively). These values were significantly lower than that measured for the phase pure C-S-H $(69.0$ $\mathrm{m}^{2} / \mathrm{g}$ ). The significantly lower values of the surface area of the C-S-H/ABA systems provide evidence of the adsorption of the aminobenzoic acid on the exterior surface of the C-S-H layers, and the blockage of the pore structure of the $\mathrm{C}-\mathrm{S}-\mathrm{H}$ by this organic compound. It is also noted that the surface area values of the C-S-H/ABA systems were smaller than that previously reported for the C-S-H/3-NBA $\left(61.2 \mathrm{~m}^{2} / \mathrm{g}\right)$ and larger than that for the C-S-H/4-NBA system $\left(32.0 \mathrm{~m}^{2} / \mathrm{g}\right)$ (Khoshnazar et al. 2014a).

\subsection{Diffusion of isopropyl alcohol}

The mass-change of the C-S-H-based systems due to the immersion in the isopropyl alcohol is shown in Fig. 4. The increase in the mass of the C-S-H-based systems during the first about 10 min after the immersion is due to the filling of the large pores by the isopropyl alcohol. The mass-reduction followed could be due to the exchange of water with the isopropyl alcohol and the removal of the interlayer water. The mass-change values of the C-S-H/3-ABA and C-S-H/4-ABA systems were very similar, and significantly lower than that of the phase pure C-S-H. This could be due to filling of some defect locations in the pore structure of $\mathrm{C}-\mathrm{S}-\mathrm{H}$ by the 3 - and 4-aminobenzoic acid. Fewer pores were, therefore, accessible to the isopropyl alcohol in the C-S-H/3-ABA and C-S-H/4-ABA systems.

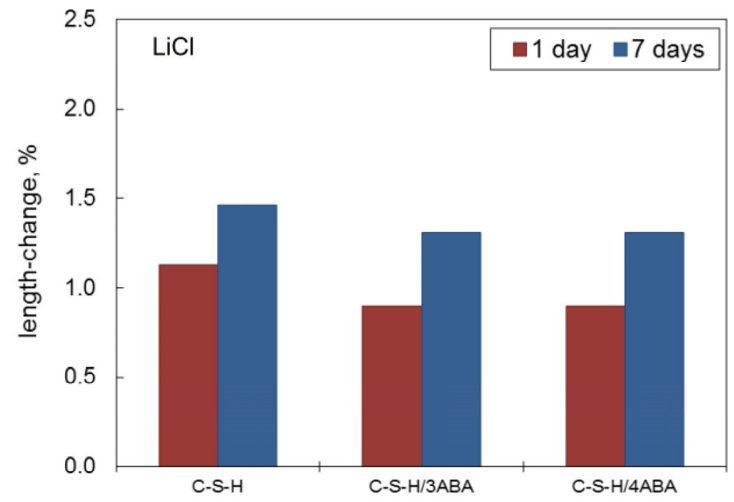

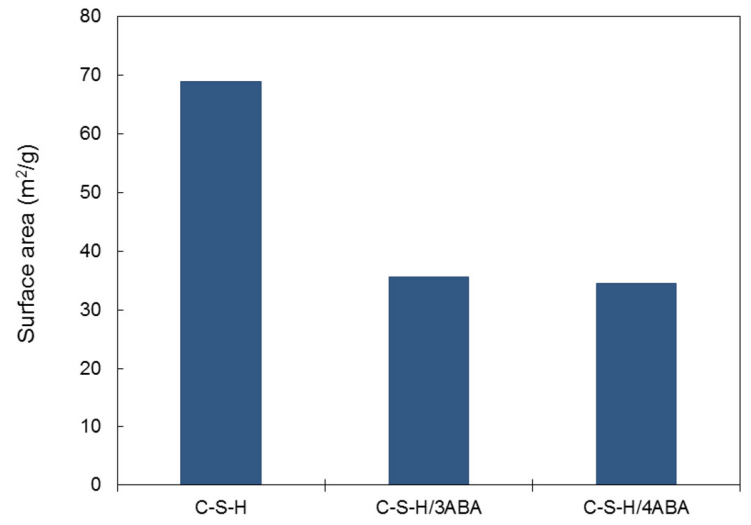

Fig. 3 BET nitrogen surface area of the phase pure C-S-H and the C-S-H/ABA systems.

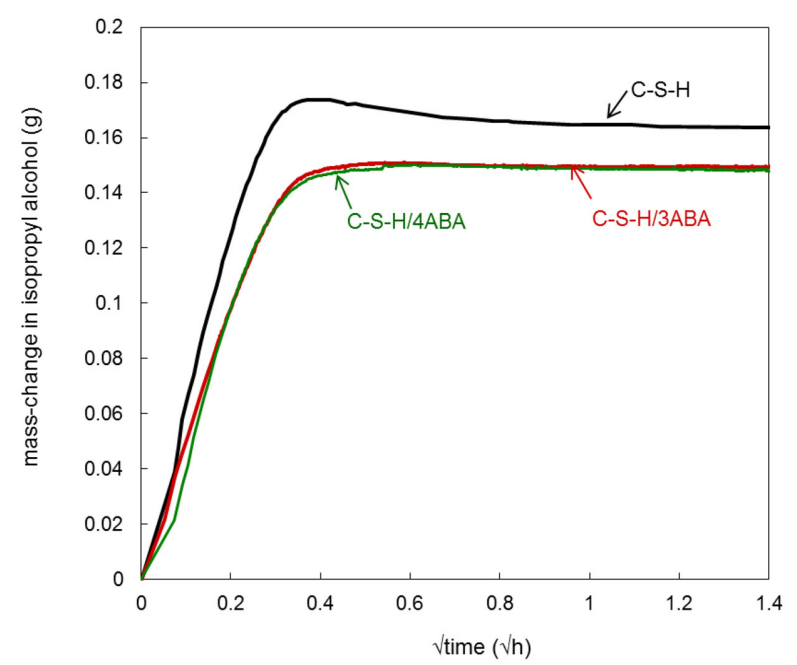

Fig. 4 Mass-change of the phase pure $\mathrm{C}-\mathrm{S}-\mathrm{H}$ and the C-S-H/ABA systems in isopropyl alcohol.

\subsection{Length-change in the test solutions}

The length-change values of the C-S-H/3-ABA and $\mathrm{C}-\mathrm{S}-\mathrm{H} / 4-\mathrm{ABA}$ systems in the test solutions were very similar, and significantly lower than those for the phase pure C-S-H (Fig. 5). In the $\mathrm{MgSO}_{4}$ solution, for example, the length-change values of the $\mathrm{C}-\mathrm{S}-\mathrm{H}$ systems with either of the 3- or 4-aminobenzoic acid were lower than those for the phase pure C-S-H by $28 \%$ and $18 \%$ after 1

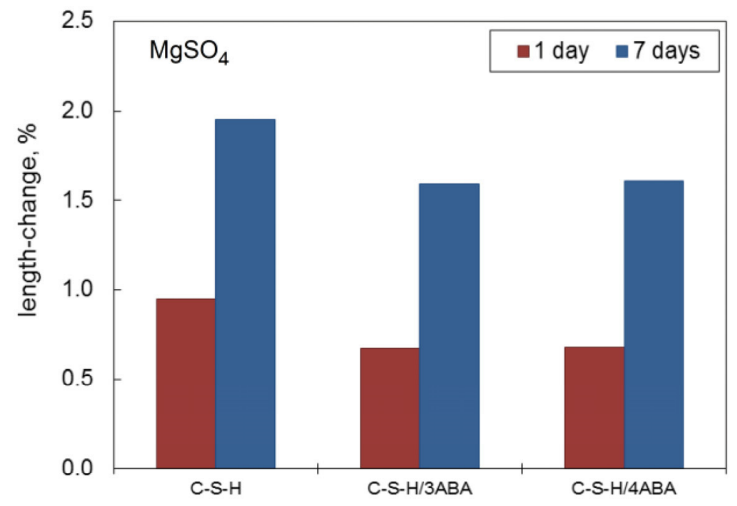

Fig. 5 Length-change of the phase pure C-S-H and the C-S-H/ABA systems in $\mathrm{LiCl}$ and $\mathrm{MgSO}_{4}$ solutions. 
day and 7 days of immersion, respectively. It has been suggested that leaching of calcium ions from the structure of C-S-H accompanied by the penetration of water and ionic species are the primary mechanisms of the expansion of the C-S-H-based systems in the aqueous solutions (Khoshnazar et al. 2014b). The two isomers of aminobenzoic acid likely filled the defect locations and blocked some of the pores in the structure of C-S-H. These could have limited both the mechanisms responsible for the expansions. In addition, the length-change values of the $\mathrm{C}-\mathrm{S}-\mathrm{H} / 3-\mathrm{ABA}$ and $\mathrm{C}-\mathrm{S}-\mathrm{H} / 4-\mathrm{ABA}$ systems were smaller than those of C-S-H/3-NBA and larger than C-S-H/4-NBA systems (Khoshnazar 2015).

\subsection{Microindentation measurements}

The creep modulus and the hardness of the C-S-H/ABA systems were compared with those of the phase pure C-S-H in Fig. 6 and 7. It was observed that the creep modulus of the C-S-H/3-ABA system $(80.8 \mathrm{GPa})$ was considerably higher than those of the C-S-H/4-ABA $(68.8 \mathrm{GPa})$ which in turn was higher than that for the phase pure C-S-H (63.4 GPa). The same trend was observed for the hardness of these systems. It has been suggested that the sliding of the silicate sheets in the nanostructure of C-S-H is the primary mechanism responsible for the creep of C-S-H systems (Nguyen et al.

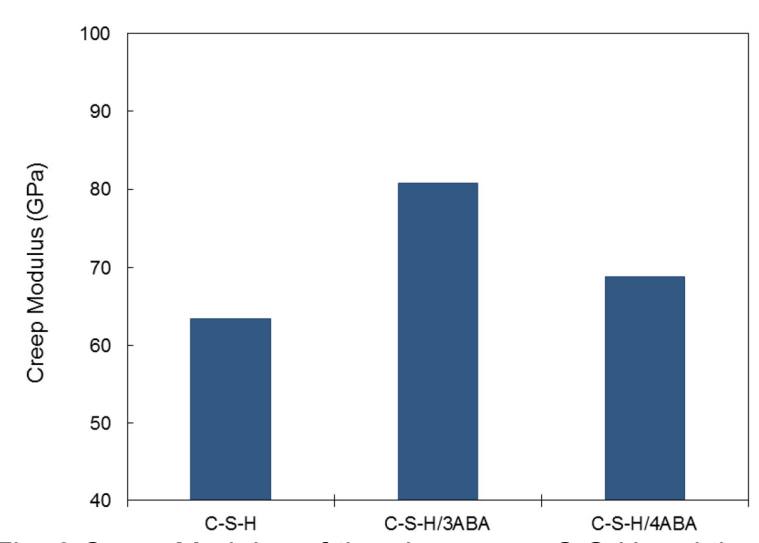

Fig. 6 Creep Modulus of the phase pure C-S-H and the C-S-H/ABA systems.

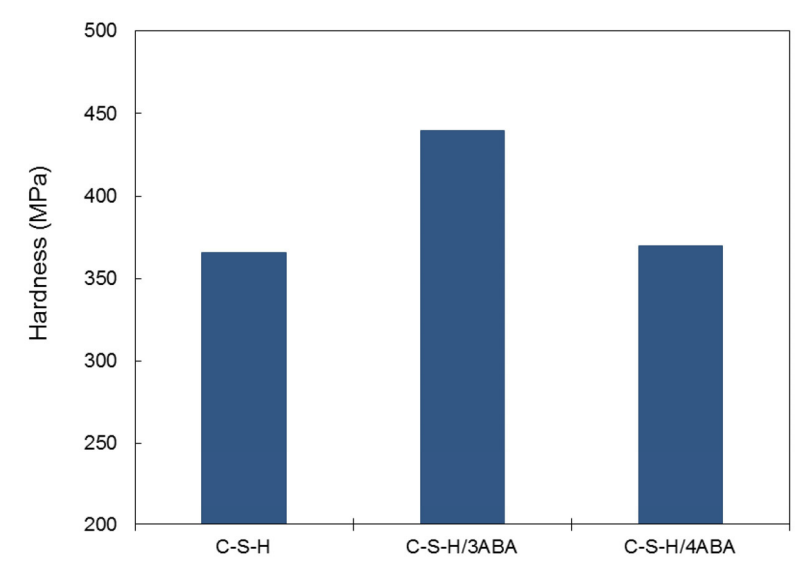

Fig. 7 Hardness of the phase pure $\mathrm{C}-\mathrm{S}-\mathrm{H}$ and the C-S-H/ABA systems.
2014). The use of the 3- and 4-aminobenzoic acid likely limited the sliding of the C-S-H sheets resulting in lower values of creep (higher values of creep modulus) of the systems.

\section{Discussion}

The results of various techniques provided evidence that the 3-ABA and 4-ABA isomers (with a concentration of 0.01 mol. per mol. of $\mathrm{Ca}$ of $\mathrm{C}-\mathrm{S}-\mathrm{H})$ are able to interact with the microstructure of C-S-H mainly by the adsorption on the surface and edges of the C-S-H layers or between the stacked layers of C-S-H. A partial intercalation in the interlayer region is also possible. These interactions resulted in an increase of about 0.03 and 0.07 $\mathrm{nm}$ in the basal-spacing, and a small shift in the location of the FTIR peaks. The adsorption of ABA isomers could also block the access points of nitrogen and isopropyl alcohol to the pore structure of the C-S-H layers. This resulted in a reduction of the BET nitrogen surface area measurements and a decrease in the isopropyl alcohol diffusion. Similarly, the length-change of the samples after immersion in the $\mathrm{LiCl}$ and $\mathrm{MgSO}_{4}$ solutions was reduced. In addition, the $\mathrm{C}-\mathrm{S}-\mathrm{H} / \mathrm{ABA}$ systems had higher values of micro-indentation creep modulus and hardness. This is an evidence of the restraining effect of the ABA isomers and limited movement of the C-S-H layers against each other in the C-S-H/ABA systems compared to the phase pure $\mathrm{C}-\mathrm{S}-\mathrm{H}$.

\section{Concluding remarks}

The effect of 3- and 4-aminobenzoic acid on the microstructure, durability and mechanical performance of $\mathrm{C}-\mathrm{S}-\mathrm{H}$ systems was investigated. Evidence was obtained that these isomers of aminobenzoic acid were able to modify the microstructure of C-S-H; mainly by the adsorption on the surface of the layers and blockage of the stacked layers of C-S-H and entry locations to the interlayer region. In addition, the aminobenzoic acid compounds likely formed some weak hydrogen bonding with the structure of the host C-S-H. It was determined using nitrogen adsorption measurements that the C-S-H/3-ABA and C-S-H/4-ABA systems had lower values of the surface area compared to those of the phase pure $\mathrm{C}-\mathrm{S}-\mathrm{H}$. The durability parameters and microindentation measurements were also improved in the C-S-H/3-ABA and C-S-H/4-ABA systems.

\section{References}

Alizadeh, R., Beaudoin, J. J., Raki, L. and Terskikh, V., (2011). "C-S-H/polyaniline nanocomposites prepared by in-situ polymerization." Journal of Materials Science, 46, 460-467.

Feldman, R. F., Sereda, P. J. and Ramachandran, V. S. (1964). "A study of length changes of compacts of Portland cement on exposure to water." Highway Research Records, 62, 106-118. 
Feldman, R. F. and Sereda P. J., (1970). "A model for hydrated Portland cement and its practical implications.” Engineering Journal, 53(8-9), 53-59.

Feldman, R. F. (1987). "Diffusion measurements in cement paste by water replacement using propan-2-ol." Cement and Concrete Research, 17, $602-612$.

Franceschini, A., Abramson, S., Mancini, V., Bresson, B., Chassenieux, C. and Lequeux, N., (2007). "New covalent bonded polymer-calcium silicate hydrate composites." Journal of Materials Chemistry, 17, 913-922.

Khoshnazar, R., (2015). "Durability of Novel C-S-H-based Nanocomposites and Secondary Hydrated Cement Phases." PhD Thesis, University of Ottawa, 268 p.

Khoshnazar, R., Beaudoin, J. J., Raki, L. and Alizadeh, R., (2014a), Interaction of 2-, 3- and 4-nitrobenzoic acid with the structure of calcium-silicate-hydrate." Materials and Structures, in-press, DOI: 10.1617/s11527-014-0513-2.

Khoshnazar, R., Beaudoin, J. J., Raki, L. and Alizadeh, R., (2014b). "Volume stability of C-S-H/polyaniline nanocomposites in aqueous salt solutions." $A C I$ Materials Journal, 111(6), 623-632.

LeBaron, P. C., Wang, Z. and Pinnavaia, T. J., (1999). "Polymer-layered silicate nanocomposites: an overview." Applied Clay Science, 15, 11-29.

Matsuyama, H. and Young, J. F., (1999a). "Intercalation of polymers in calcium silicate hydrate: A new synthetic approach to biocomposites?" Chemistry of Materials, 11, 16-19.

Matsuyama, H. and Young, J. F., (1999b). "Synthesis of calcium silicate hydrate/polymer complexes: Part I." Journal of Materials Research, 14, 3379-3388.

Matsuyama, H. and Young, J. F., (1999c). "Synthesis of calcium silicate hydrate/polymer complexes: Part II." Journal of Materials Research, 14, 3389-3396.

Merlin, F., Lombois, H., Joly, S., Lequeux, N., Halary, J.-L. and Van-Damme, H., (2002). "Cement-polymer and clay-polymer nano- and meso-composites: spotting the difference." Journal of Materials Chemistry, $12,3308-3315$.

Minet, J., Abramson, S., Bresson, B., Sanchez, C., Montouillout, V. and Lequeux, N., (2004). "New layered calcium organosilicate hybrids with covalently linked organic functionalities." Chemistry of Materials, $16,3955-3962$.

Minet, J., Abramson, S., Bresson, B., Franceschini, A., Van Damme, H. and Lequeux, N., (2006). "Organic calcium silicate hydrate hybrids: a new approach to cement based nanocomposites." Journal of Materials Chemistry, 16, 1379-1383.

Mojumdar, S. C. and Raki, L., (2006). "Synthesis, thermal and structural characterization of nanocomposites for potential applications in const- ruction." Journal of Thermal Analysis and Calorimetry, 86, 651-657.

Natkanski, P., Kustrowski, P., Bialas, A., Piwowarska, Z. and Michalik, M. (2012). "Controlled swelling and adsorption properties of polyacrylate/montmorillonite composites." Materials Chemistry and Physics, 136, 1109-1115.

Nguyen, D., Alizadeh, R., Beaudoin, J. J., Pourbeik, P. and Raki, L., (2014). "Microindentation creep of monophasic calcium-silicate-hydrates." Cement and Concrete Composites, 48, 118-126.

Okada, A., kawasumi, M., Usuki, A., Kurauchi, T. and Kamigaito, O., (1990). "Synthesis and properties of nylon-6/clay hybrids." Polym. molecul compos. In: D.W. Schaefer and J. E. Mark Eds, MRS Symposium Proceedings, Pittsburgh, 171, 45-50.

Oliver, W. C. and Pharr, G. M., (1992). "An improved technique for determining hardness and elastic modulus using load and displacement sensing indentation experiments." Journal of Materials Research, 7, 1564-1583.

Ramachandran, V. S., Beaudoin, J. J. and Paroli, R. M., (1991). "The effect of nitrobenzoic and aminobenzoic acids on the hydration of tricalcium silicate: a conduction calorimetric study." Thermochimica Acta, 190, 325-333.

Samsonowicz, M., Hrynaszkiewicz, T., Świsłocka, R., Regulska, E. and Lewandowski, W., (2005). "Experimental and theoretical IR, Raman, NMR spectra of 2-, 3- and 4-aminobenzoic acids." Journal of Molecular Structure, 744-747, 345-352.

Samsonowicz, M., Świsłocka, R., Regulska, E. and Lewandowski, W., (2007). "Experimental and theoretical IR, Raman, NMR spectra of 2-, 3-, and 4-nitrobenzoic acids." International Journal of Quantum Chemistry, 107, 480-494.

Sereda, P. J. and Feldman, R. F., (1963). "Compact of powdered materials as porous bodies for use in sorption studies." Journal of Applied Chemistry, 13(4), 150-158.

Somwangthanaroj, A., Ubankhlong, W. and Tanthapanichakoon, W., (2010). "Solid-state mechanical properties of polypropylene/nylon6/clay nanocomposites." Journal of Applied Polymer Science, $118,538-546$.

Taylor, H., (1997). "Cement Chemistry." 2nd Edition, London: Thomas Telford Publication.

Vandamme, M., (2008). "The nanogranular origin of concrete creep: a nanoindentation investigation of microstructure and fundamental properties of calcium-silicate-hydrates." $\mathrm{PhD}$ Thesis, Massachusetts Institute of Technology, $366 \mathrm{p}$.

Yu, P., Kirkpatrick, R. J., Poe, B., McMillan, P. and Cong, X., (1999). "Structure of calcium silicate hydrate (C-S-H): Near-, mid-, and far-infrared spectroscopy." Journal of American Ceramic Society, 82(3), 742-748. 